\title{
Analysis and Correction of Noise on Electronic Circuits in an Accelerator
} Environment 1

\author{
M. Fathizadeh, O.D. Despe, D.G. McGhee \\ Argonne National Laboratory, APS \\ 9700 S. Cass Avenue, Argonne, II 60439
}

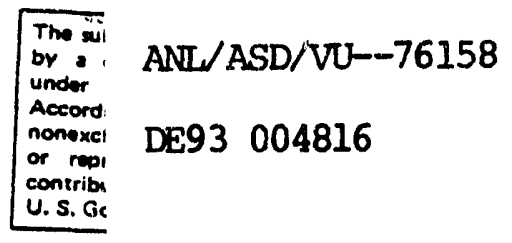

\section{Abstract}

Accelerator noise sources can cause both analog and digital electronic circuits to malfunction. This paper identifies and analyzes noise sources, and describes the methodology for measurement. Both general remedies and specific solutions to minimize the noise effects on accelerator electronic circuits are described. A policy for electronic design, board layout assembly, and fabrication is established. Conclusions are drawn based on theoretical principles with practical examples shown in case studies.

\section{INTRODUCTION}

In an accelerator facility, many sensitive electronic circuits are used for triggering, control, monitoring, and data acquisitions. Switching and phase controlled dc power supplies, pulsed magnets, and large magnetic fields can create a noisy environment which cause electronic circuits to malfunction and consequently jeopardize the safe and corres: operation of the facility. Introduction of noise from certain equipment into the line can cause other equipment fed from the same line to malfunction. Most of the equipment available commercially does not provide any specification regarding the input line quality.

Noise can be transferred through conduction, inductance and/or capacitance coupling, and radiation. Electrical noise is conducted via common ground impedances, power lines, and interconnecting cables. However, noise can be radiated and received by antenna-to-antenna (conductor-to-conductor), through case penetrations [1]. These noise signals can appear in the form of continuous, transient, or offset voltages and currents. A transient voltage disturbance is generally classified into two different types: normal mode and common mode, according to where it occurs on a signal conditioning system. Normal mode transient voltage appears between any power or signal conductors as long as none of the lines are ground or common conductor. On the other hand, common mode transient voltage generally appears equally and in phase from each signal conductor to ground. Power supply signals can be classified as noisy and quiet signals. The integration of all control and power components must be carefully done to minimize the noise propagation in the system.

\footnotetext{
1 Work supponed by U.S. De, tment of Energy, Office of Basic Energy Sciences under Coniract No. W-31-109-ENG-38.
}

In order to minimize the penetration and transfer of noise to sensitive electronic circuits, several precautionary measures must be taken. These precautions must be practiced during the design of power circuits, control circuits, printed circuit board (PCB) layouts, wiring distribution and connections, and finally the manufacturing. In cases where both analog and digital signals are present (usually the case), the analog signal is more susceptible to noise generated by the fast transients of the digital signals. It is best to use the power grounding (safety) conductor for power grounding only. For signal-reference ground, a separate, low impedance path is preferable. Separate grounding buses for digital signals, for analog signals, and high ground currents to eliminate undesired coupling of signals via common ground leads should be used. The use of optical coupling is also recommended in order to reduce noise transfer into electronic circuits and provide galvanic isolation between them. To minimize mutual inductances, minimize loop areas.

The controlled and uncontrolled power supplies can introduce current components into the line in the form of the harmonics or sub-harmonics of the line frequency. These harmonics can be troublesome for the operation of sensitive electronic equipment [2].

\section{HARMONIC ANALYSIS}

The power supplies used in an accelerator system can be phased controlled, switched mode, or pulse type power supplies. In the switched mode supplies, the chopper frequency is usually in the tens or hundreds of $\mathrm{kHz}$; this makes the filtering problem generally simpler than in-line frequency phase controlled supplies. When a large amount of dc current is needed, phase controlled power supplies are used. These power supplies are usually 6- or 12-pulse units. Due to the usually low ripple requirements of these power supplies the 12-pulse ones are utilized more frequently. For a balanced system, the input current harmonics for 6- or 12 . pulse power supplies are calculated by the expressions given below:

$$
\begin{aligned}
& \mathrm{i}_{\mathrm{a}}=\frac{2 \mathrm{~m} \sqrt{3}}{12 \mathrm{~N}_{\mathrm{p}}} \mathrm{I}_{\mathrm{d}}\left[\cos \omega \mathrm{t}-\frac{1}{(\mathrm{mp}-1)} \cos (\mathrm{mp}-1) \omega t\right. \\
& \left.+\frac{1}{(m p+1)} \cos (m p+1) \omega t\right) \\
& \text { MASTER } \\
& \text { DISTRLBUTLAN OF THLS DOSUMENT IS UNLIAITEN }
\end{aligned}
$$




\section{DISCLAIMER}

This report was prepared as an account of work sponsored by an agency of the United States Government. Neither the United States Government nor any agency thereof, nor any of their employees, makes any warranty, express or implied, or assumes any legal liability or responsibility for the accuracy, completeness, or usefulness of any information, apparatus, product, or process disclosed, or represents that its use would not infringe privately owned rights. Reference herein to any specific commercial product, process, or service by trade name, trademark, manufac: turer, or otherwise does not necessarily constitute or imply its endorsement, recommendation, or favoring by the United States Government or any agency thereof. The views and opinions of authors expressed herein do not necessarily state or reflect those of the United States Government or any agency thereof. 
where $I_{d}$ is the dc current in the magnet, $N$ is the transformer tum ratio, and $i_{2}$ is the ac input line current. The output voltage harmonics are given as:

$$
\begin{array}{r}
V_{b}=\frac{\sigma V_{m}}{\pi} \sum_{p=1}^{\infty}(-1)^{p} \frac{\cos (m p \omega t+(m p+1) \alpha)}{(m p+1)} \\
\left.. \frac{\cos (m p \omega t+(m p-1) \alpha)}{(m p-1)}\right\}
\end{array}
$$

where $V_{m}$ is the peak voltage value of the ac source, $\alpha$ is the firing angle of the converter, $\omega$ is the line frequency, $p$ is the harmonic order, and $m=6$ for a 6 -pulse power supply and $m=12$ for a 12 -pulse power supply where $p=1,2, \ldots$.

The above equations indicate that the line current has harmonics of the order $\mathrm{h}=\mathrm{mp} \pm 1$, and the output voltage contains harmonics of order $h=m p$.

The harmonic currents injected into the utility line by the power supply can be reduced by addition of filters to the input of the power supply.

To quantify the distortion in the current waveform, a quantity called the total harmonic distortion (THD), is defined as follows:

$$
\mathrm{THD}=\frac{\sqrt{\sum_{2}^{\infty}\left(\mathrm{I}_{\mathrm{h}}\right)^{2}}}{\mathrm{I}_{1}}
$$

where $I_{1}$ is the fundamental current of the input line. The above equation can also be used to calculate THD for the output voltage if $I_{h}$ is replaced by output voltage harmonics, $V_{b}$ and $I_{1}$ is replaced by $V_{1}$. The above analysis is developed for balanced systems whereas in reality phase imbalances can occur and cause generation of other harmonics in the input line.

\section{A. Case Study 1}

The input ac line voltage can be imbalanced, for example, when one phase is loaded more than the other two. The phase imbalance of the input ac line can cause generation of unwanted harmonics in the input and output of the phase controlled power supplies. Table-1 shows the actual measured THD or input current harmonics of 6- and 12-pulse power supplies fed from a balanced system while Table-2 shows the THD for 6- and 12-pulse power supplies when they are fed from a three phase system with $5 \%$ input phase voltage imbalance. The actual input line current harmonics for 6- and 12-pulse power supplies under the above conditions are also plotted and shown in Figures 1 through 4. A Tektronix 100 A current probe with a current amplifier is used to measure the input current. The fast Fourier transform (FFT) is calculated by using a DSA-602 Tektronix scope.
Table-1. Harmonic Contents of Input Line Current of Phase Controlled PS with No Phase Imbalance

\begin{tabular}{|lll|}
\hline Type of PS & Components & THD \\
\hline Six Pulse & $1,5,7,11,13, \ldots$ & $15 \%$ \\
Twelve Pulse & $1,11,13, \ldots$ & $8 \%$ \\
\hline
\end{tabular}

Table-2 Harmonic Contents of Input Line Current of Phase Controlled PS Due to 5\% Phase Imbalance

\begin{tabular}{|lll|}
\hline Type of PS & Components & THD \\
\hline Six Pulse & $1,3,5,7,9,11,13, \ldots$ & $22 \%$ \\
Twelve Pulse & $1,3,9,11,13 \ldots$ & $17 \%$ \\
\hline
\end{tabular}

Figures 1 and 3 are the FFT plots for 6- and 12-pulse power supplies under normal condition and Figures 2 and 4 are FFT plots for line currents under 5\% phase imbalance. Under the 5\% phase voltage imbalance the multiple of three harmonic components appear in the ac line current in addition to the existing harmonics presented in the phase balanced case; and they are almost as severe as higher frequency harmonic components.

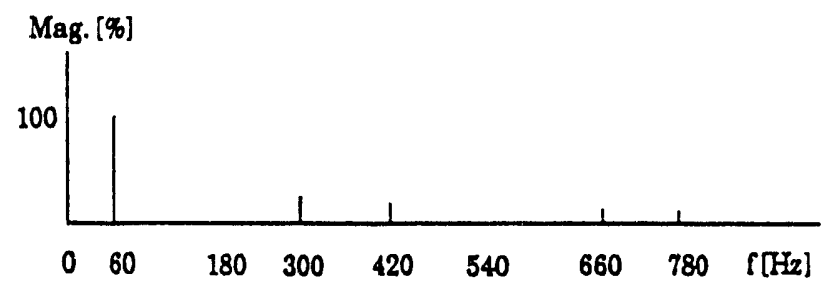

Figure 1 Input Current Spectrum for a 6-Pulse Power Supply Without Phase Imbalance.

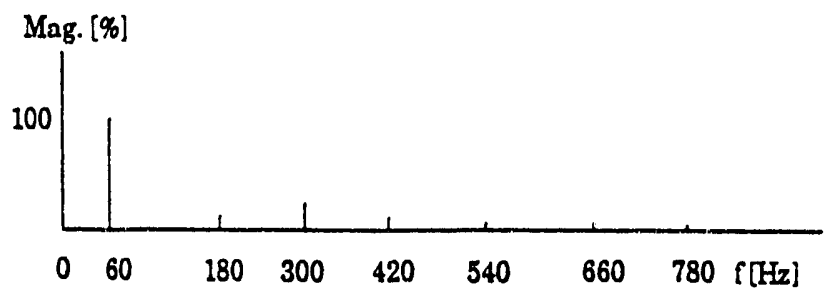

Figure 2 Input Current Spectrum for a 6-Pulse Power Supply With 5\% Phase Voltage Imbalance.

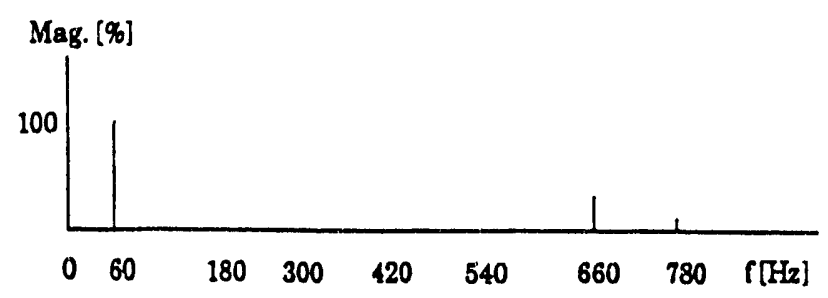

Figure 3 Input Current Spectrum for a 12-Pulse Power Supply Without Phase Imbalance. 


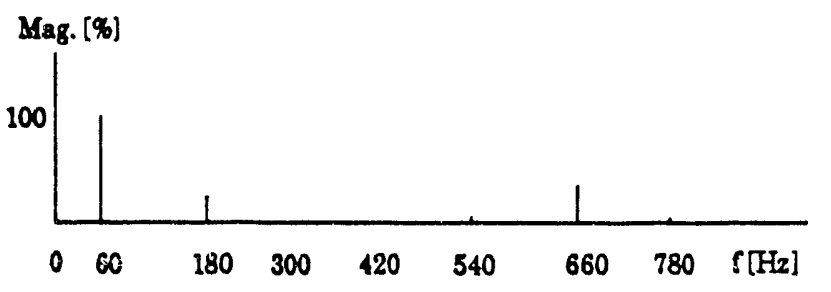

Figure 4 Input Current Spectrum for a 12-Pulse Power Supply With 5\% Phase Voltage Imbalance.

The lowest frequency for the harmonic is the fundamental one and the phase imbalance does not cause the generation of sub-harmonic components. However, switched-mode power supplies connected to the ac power system can cause subharmonic components to appear in the ac line. Comparison of Figures 2 and 4 shows that a 12-pulse power supply introduces a smaller amount of harmonic current into the line than a 6-pulse supply.

\section{B. Case Study 2}

Switched mode power supplies in high power applications are generally fed from a raw phase controlled power supply with a typical R-L-C ol'put filter. The output filter characteristics of the raw power supply may cause problems when it is feeding a switched mode converter as its load. The raw power supply output filter is typically near critically damped in order to improve the overall efficiency. The R-L$C$ filter can give rise to low frequency oscillations at its output when it is subjected to periodic load changes, such as when supplying power to a switched mode converter. Usually large input capacitance of a switched-mode power converter can make the overall filter response underdamped. Therefore, significant step current loads or loads of frequency at or near harmonics of the filter's natural resonant frequency can cause an oscillation. The following case study is presented to illustrate the phenomenon of the above discussion.

A 6-pulse, phase controlled power supply (Table-3) was used to feed a chopper (Table-4). After connection of the chopper to the phase controlled power supply, an oscillation with frequency of about $16 \mathrm{~Hz}$ was observed at the output of the chopper. Further investigation of the problem showed the oscillations originated from the raw supply output. The specifications for both the phase controlled and switched mode (chopper) power supplies are given in the following tables.

Table-3 Phased Controlled PS Specification

\begin{tabular}{|lll|}
\hline Input Voltage & 480 & $\mathrm{~V}$ \\
Input Frequency & 60 & $\mathrm{~Hz}$ \\
Output Filter, L & 1.03 & $\mathrm{mH}$ \\
Output Filter C1 & 7500 & $\mu \mathrm{F}$ \\
Output Filter C2 & 37000 & $\mu \mathrm{F}$ \\
Output Voltage & 0.80 & $\mathrm{~V}$ \\
Output Current & 0.1200 & $\mathrm{~A}$ \\
\hline
\end{tabular}

Table-4 Chopper Specification

\begin{tabular}{|lll|}
\hline Input Voltage & 45 & $\mathrm{~V}$ \\
Input Capacitance & 44800 & $\mu \mathrm{F}$ \\
Chopper Frequency & 20 & $\mathrm{kHz}$ \\
Output Current & 0.450 & $\mathrm{~A}$ \\
Output Volage & 0.30 & $\mathrm{~V}$ \\
\hline
\end{tabular}

The calculated natud resonant frequency is $\mathrm{f}_{\mathrm{r}}=16.59 \mathrm{~Hz}$, for $L=1.03 \mathrm{mH}$ and $C=89300 \mu \mathrm{F}$, and the measured frequency of the oscillation is about $16 \mathrm{~Hz}$. The filter inductance was reduced to $100 \mu \mathrm{H}$ to obtain a higher natural resonant frequency and a damping factor ten times higher than before. The change in damping factor also improved the time response of the output filter and the voltage drop due to the filter at the output of the phase controlled power supply is reduced. This eliminated the oscillation.

\section{CONCLUSION}

A discussion is presented to give an understanding of the generation and propagation of noise in the electrical system in an accelerator system. Some approaches are discussed to reduce or eliminate the effect of noise on the electronic circuits. Recommendations in design, wiring, and connections are made. The use of separate ground leads for digital and analog signals to eliminate the undesired coupling of signals via common ground leads is also covered. In mixed mode PCBs the importance of physical separations between analog and digital circuits is emphasized. In general, for analog signal transmission, use of differential mode to reduce common mode noise and shielded twisted pairs to minimize noise pick-up are recommended. Optical coupling can be used to reduce noise transfer into electronic circuits.

The ground conductor slould be used only for grounding purposes. The use of long cables for data transmission must be in accordance with the manufacturer's specifications and other applicable standards to improve the $S / N$ ratio of the transmitted signals.

In three phase systems care must be taken to reduce the amount of phase imbalance due to improper loading of different phases. A 6- or 12-pulse power supply fed from a balanced three phase system introduces less current harmonic back into the line than when it is fed from an imbalanced system

\section{REFERENCES}

[1] Don White, Course on Electromagnetic Compatibility, Interference Control Technology, 1990.

[2] James Nadolny, " Power Supply Layout Guidelines," EMC Technology , Vol 11/Number 2, March/April 1992. 

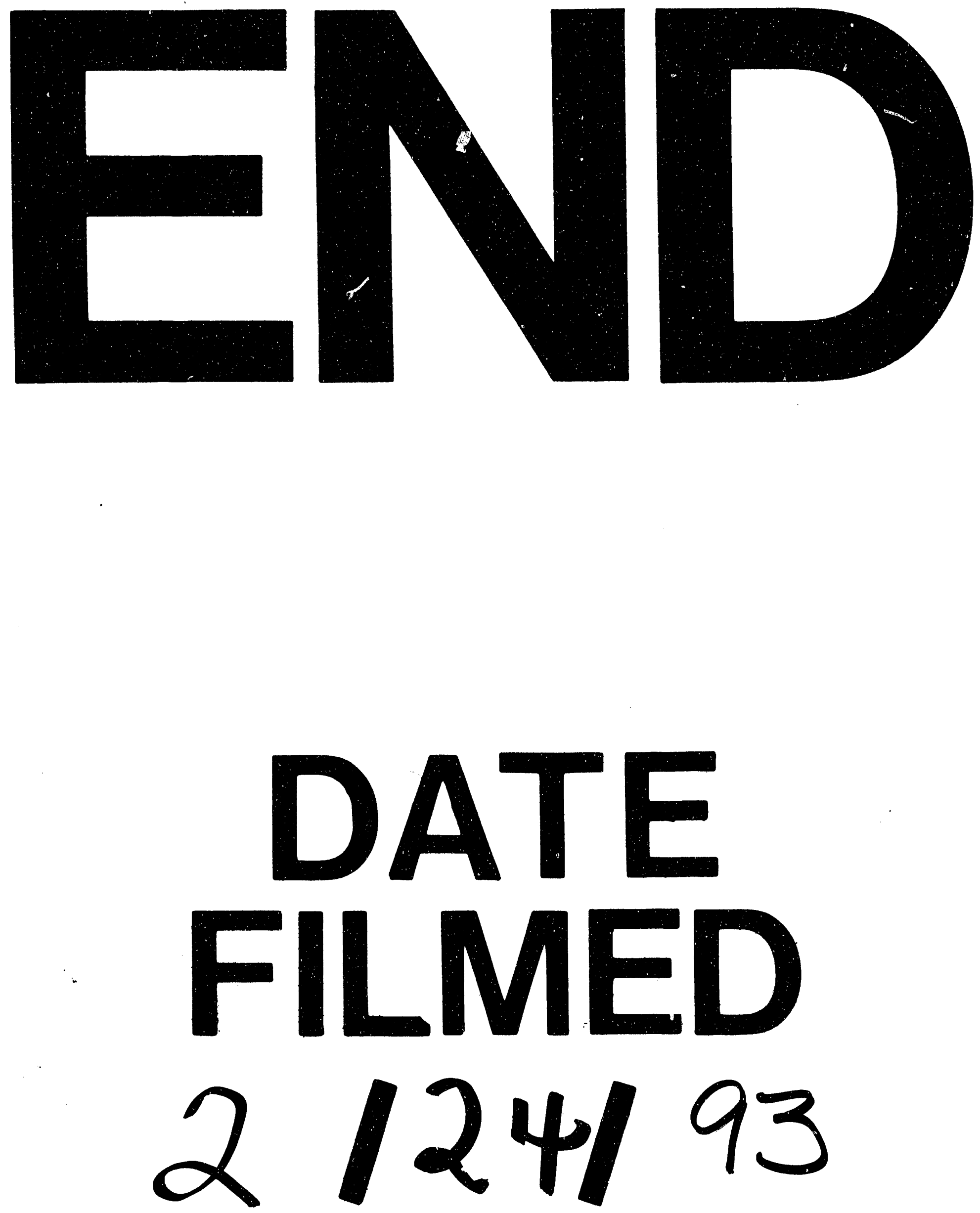
